ARTICLE

Received 12 Aug 2014 | Accepted 27 Oct 2014 | Published 5 Dec $2014 \quad$ DOl: 10.1038/ncomms6687

\title{
Crystalline-gradient polycarbonates prepared from enantioselective terpolymerization of meso-epoxides with $\mathrm{CO}_{2}$
}

Ye Liu', Wei-Min Ren ${ }^{1}$, Ke-Ke He${ }^{1} \&$ Xiao-Bing Lu

The development of efficient processes for $\mathrm{CO}_{2}$ transformation into useful products is a long-standing goal for chemists, since $\mathrm{CO}_{2}$ is an abundant, inexpensive and non-toxic renewable $\mathrm{C} 1$ resource. Here we describe the enantioselective copolymerization of 3,4-epoxytetrahydrofuran with $\mathrm{CO}_{2}$ mediated by biphenol-linked dinuclear cobalt complex, affording the corresponding polycarbonate with $>99 \%$ carbonate linkages and excellent enantioselectivity (up to $99 \%$ enantiomeric excess). Notably, the resultant isotactic polycarbonate is a typical semicrystalline polymer, possessing a melting point of $271^{\circ} \mathrm{C}$. Furthermore, the enantioselective terpolymerization of 3,4-epoxytetrahydrofuran, cyclopentene oxide and $\mathrm{CO}_{2}$ mediated by this dinuclear cobalt complex gives novel gradient polycarbonates, in which the decrement of one component and the increment of the other component occur sequentially from one chain end to the other end. The resultant terpolymers show perfectly isotactic structure and have unique crystalline-gradient nature, in which the crystallinity continuously varies along the main chain.

\footnotetext{
${ }^{1}$ State Key Laboratory of Fine Chemicals, Dalian University of Technology, Dalian 116024, China. Correspondence and requests for materials should be addressed to X.-B.L. (email: xblu@dlut.edu.cn).
} 
T he utilization of carbon dioxide $\left(\mathrm{CO}_{2}\right)$ as a $\mathrm{Cl}$ source for the production of useful chemicals has received intense attention in recent decades ${ }^{1-5}$. This is motivated by the economic and environmental benefits arising from the use of the abundant renewable resource and the growing concern on the greenhouse effect. Conforming to this objective, the alternating copolymerization of $\mathrm{CO}_{2}$ with epoxides for the synthesis of degradable polycarbonates is one of the most promising green reactions, which was first demonstrated by Inoue et al. ${ }^{6}$ Subsequent to the early discovery, numerous heterogeneous and well-defined homogeneous catalysts have been developed for this important transformation ${ }^{7-13}$. Despite the tremendous progress made in this field, most of the $\mathrm{CO}_{2}$-based polycarbonates are known to be amorphous, and their low thermal resistance makes them difficult to use as structural materials. In a recent study, we reported a typical semicrystalline polymer, isotactic poly(cyclohexene carbonate), prepared by enantioselective copolymerization of $\mathrm{CO}_{2}$ with meso cyclohexene oxide ${ }^{14}$. It was also found that the isotacticity had the critical influence on the crystallinity of poly(cyclohexene carbonate)s. Following this investigation, several crystalline $\mathrm{CO}_{2}$-based polycarbonates with good thermal stability were discovered $^{15-17}$.

Since the relative stereochemistry of adjacent stereocentres in a defined polymer has a significant effect on its thermal and physical properties, precise control of a polymer's stereoregularity is an important goal in polymerization catalysis ${ }^{18}$. Recently, Kamigaito's group ${ }^{19,20}$ reported a new class of polymers, stereogradient polymers, produced from the stereospecific living radical copolymerization of two monomers with different reactivities and stereospecificities. In these stereogradient polymers, the tacticity continuously changes from one chain end to the other end, unlike traditional stereoblock or -random copolymers. Following their excellent catalyst design of salen-type cobalt complex with a piperidinium endcapping $\mathrm{arm}^{21}$, Nozaki and coworkers ${ }^{22}$ reported a novel stereogradient, poly(propylene carbonate)s (PPCs), consisting of two enantiomeric structures on each end, prepared by this cobalt complex-mediated regio- and enantioselective copolymerization of racemic propylene oxide with $\mathrm{CO}_{2}$. The iso-enriched stereogradient PPC starts from an $(S)$-rich PPC block and ends with an $(R)$-rich PPC block. Notably, the obtained stereogradient PPCs were found to possess higher thermal decomposition temperature than the typical PPCs ${ }^{23}$.

Herein, we describe a synthetic strategy of preparing crystalline-gradient polycarbonates by dinuclear cobalt(III) complex-mediated enantioselective terpolymerization of meso-3,4epoxytetrahydrofuran (COPO), cyclopentene oxide (CPO) and $\mathrm{CO}_{2}$, in which two epoxides have different reactivities in terpolymerizing with $\mathrm{CO}_{2}$. Crystalline-gradient polycarbonates can be defined as polymers in which the crystallinity sequentially varies along the main chain and have never been reported previously.

\section{Results}

Synthesis of isotactic polycarbonates from COPO. MesoCOPO, consisting of a three-membered epoxy-ring and a fivemembered ring with one oxygen atom, perhaps has a relatively high reactivity in coupling with $\mathrm{CO}_{2}$ by its epoxy-ring in the presence of a metal catalyst, while the oxygen atom in the fivemembered ring makes it have obvious difference in comparison with CPO, a previously studied meso-epoxide ${ }^{24}$. Recently, we developed a chiral catalyst system based on the biphenol-linked dinuclear Co(III) complex (Fig. 1), which exhibited excellent activity, unprecedented enantioselectivity and molecular-weight control for the alternating copolymerization of $\mathrm{CO}_{2}$ with mesoepoxides such as $\mathrm{CPO}$ under mild reaction conditions ${ }^{25}$. Previously, Coates and co-workers ${ }^{26-28}$ have demonstrated that the dinuclear cobalt complexes based on binaphthol linker were highly active and enantioselective for homopolymerization of terminal epoxides. As a consequence, the same enantiopure biphenol-linked dinuclear Co(III) complex was employed as catalyst for enantioselective copolymerization of $\mathrm{CO}_{2}$ with COPO. As expected, the catalyst exhibited excellent enantioselectivities under mild conditions. The screening experimental results are summarized in Table 1 . The dinuclear cobalt complex $(S, S, S, S)$-1 alone as catalyst could catalyse the coupling reaction at room temperature to afford the corresponding copolymer with $85 \%$ enantioselectivity for $S, S$-configuration excess, although the activity was not satisfactory (Table 1, entry 1). The copolymer enantioselectivity is based on the enantiomeric excess (ee) of the dibenzoate of the diol that resulted from the hydrolysis of the resultant polycarbonates, as determined by chiral highperformance liquid chromatography (Supplementary Methods). The presence of PPNX (PPN = bis(triphenylphosphine)iminium, $\mathrm{X}=2$,4-dinitrophenoxide) as cocatalyst significantly improved both activity (a turnover frequency (TOF) of $170 \mathrm{~h}^{-1}$ ) and enantioselectivity ( $95 \%$ ee) (Entry 2 ). It should be noted that the resultant copolymers possess perfectly alternating nature with $>99 \%$ carbonate unit content (Fig. 2 and Supplementary Fig. 1) and neither the cyclic carbonate byproduct nor the polyether linkage was found in the two systems. The reaction temperature has a strong influence on both enantioselectivity and activity for this asymmetric copolymerization process. For example, when the reaction temperature decreased from 25 to $0{ }^{\circ} \mathrm{C}$, the enantioselectivity of the resulting polycarbonates increased from 95\% to 99\% (Table 1, entry 3 and Supplementary Figs 6 and 7). Similar activity and enantioselectivity were also observed in the $(R, R, R, R)$-1-mediated $\mathrm{CO}_{2} / \mathrm{COPO}$ copolymerization, providing the copolymer with $R, R$-configuration absolutely (Entry 4). When the dinuclear cobalt catalyst system was performed at $50{ }^{\circ} \mathrm{C}$, providing a completely alternating copolymer with an enantioselectivity of $90 \%$ ee for $S, S$-configuration, the activity was increased to $458 \mathrm{~h}^{-1}$ (Entry 5). On increasing the $[\mathrm{COPO}] /[(S, S, S, S)-1]$ ratio from 1,000 to 2,000 , the TOF was decreased from 170 to $132 \mathrm{~h}^{-1}$; however, the enantioselectivity was maintained at a high level (Entry 6).

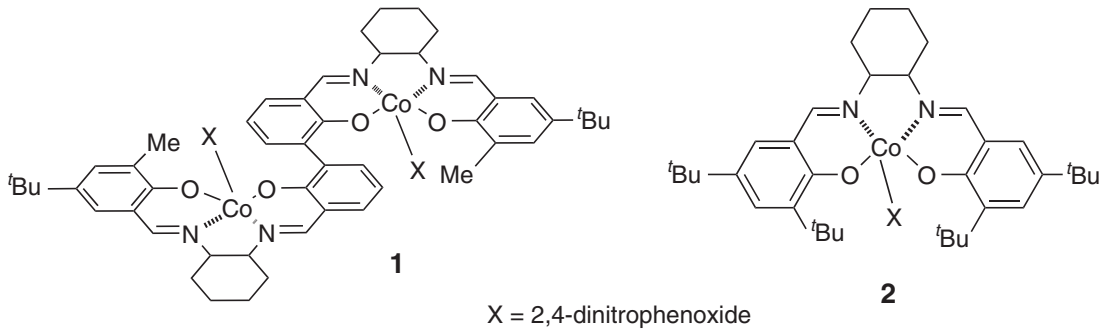

Figure 1 | Structure of Co(III)-Salen complex. Full synthesis procedure and characterization are provided in the Supplementary Methods. 
Table 1 | Enantiopure Co(III)-complex-mediated asymmetric copolymerization $\mathrm{CO}_{2}$ with $\mathrm{COPO}^{\star}$.

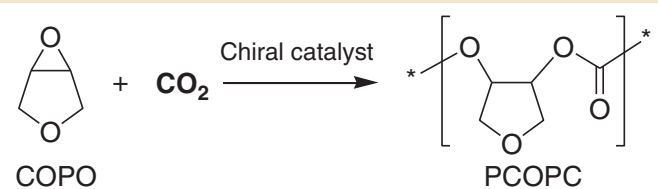

\begin{tabular}{|c|c|c|c|c|c|c|c|c|}
\hline Entry & Catalyst & Catalyst/PPNX/COPO & Temp $\left({ }^{\circ} \mathrm{C}\right)$ & Time (h) & TOF $^{\ddagger}\left(h^{-1}\right)$ & $M_{\mathrm{n}}^{\S}\left(\mathrm{kg} \mathrm{mol}^{-1}\right)$ & PDI $\$$ & ee ${ }^{\|}(\%)$ \\
\hline 1 & $(S, S, S, S)-\mathbf{1}$ & $1 / 0 / 1,000$ & 25 & 48 & 3 & 11.6 & 1.12 & $85(S, S)$ \\
\hline 3 & $(S, S, S, S)-1 / P P N X$ & $1 / 2 / 1,000$ & 0 & 24 & 21 & 10.9 & 1.16 & $>99(S, S)$ \\
\hline 5 & $(S, S, S, S)-1 / P P N X$ & $1 / 2 / 1,000$ & 50 & 1 & 458 & 15.3 & 1.12 & $90(S, S)$ \\
\hline 6 & $(S, S, S, S)-1 / P P N X$ & $1 / 2 / 2,000$ & 25 & 6 & 132 & 15.6 & 1.15 & $95(S, S)$ \\
\hline $7^{\bullet}$ & $(S, S, S, S)-1 / P P N X$ & $1 / 2 / 1,000$ & 25 & 12 & 83 & - \# & - & $98(S, S)$ \\
\hline 8 & rac-2/PPNX & $1 / 1 / 500$ & 25 & 48 & 4 & 8.2 & 1.21 & 0 \\
\hline
\end{tabular}

*The reaction was performed in neat COPO $(30 \mathrm{mmol})$ in $20 \mathrm{ml}$ autoclave. $\mathrm{X}=2,4$-dinitrophenoxide. The selectivity for polycarbonates over cyclic carbonate and carbonate linkages of all the resultant polymers is $>99 \%$ based on ${ }^{1} \mathrm{H}$ NMR spectroscopy.

† Molar ratio.

$\ddagger$ Turnover frequency $($ TOF $)=$ mole of product (polycarbonates) $/ \mathrm{mol}$ of cat per hour.

\$The polymer was heated to $280^{\circ} \mathrm{C}$ and determined by gel permeation chromatography in DMF, calibrated with polystyrene.

||Hydrolysing the polymer, derivatizing the resultant diol using benzoyl chloride, and then determining the ee of the dibenzoate by HPLC.

- The reaction was carried out in dichloromethane solution with $\mathrm{COPO} /$ dichloromethane $=1: 2$ (volume ratio).

\#The polymer with high molecular weight and isotacticity was not soluble in THF, chloroform or DMF; even in $1,2,4-\mathrm{Cl}_{3} \mathrm{C}_{6} \mathrm{H}_{3}$, the $\mathrm{M}_{\mathrm{n}}$ and PDI could not be determined.

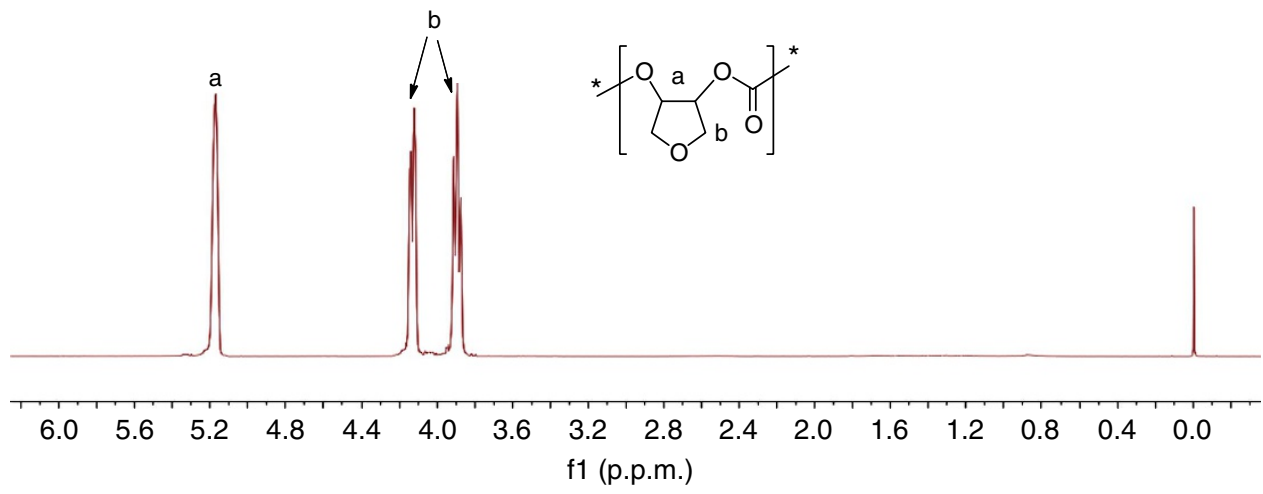

Figure 2 | ${ }^{\mathbf{H}}$ NMR spectrum of a representative sample of PCOPC in $\mathbf{C D C l}_{\mathbf{3}}$. The polymer was purified by using DMSO/MeOH. (a) Methine hydrogen atoms; (b) methylene hydrogen atoms. ${ }^{\star}$ Repeat carbonate unit of polymers.
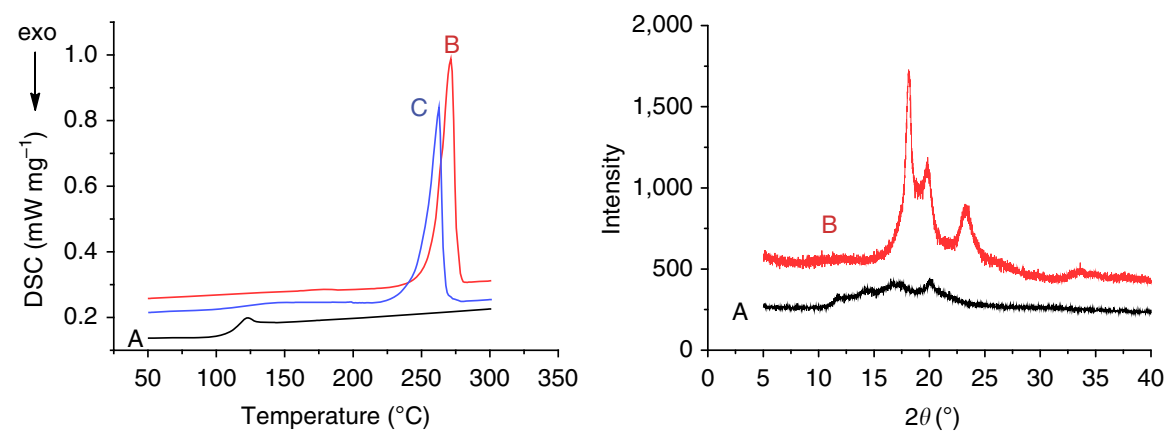

Figure 3 | DSC thermograms and WAXD profiles of various PCOPCs. DSC thermograms (left) in second heating and WAXD profiles (right) of (A) atactic PCOPC (ee =0\%, Table 1, entry 8), (B) highly isotactic PCOPC (ee $>99 \%$, Table 1, entry 3 ) and (C) PCOPC with moderate isotacticity (ee $=85 \%$, Table 1, entry 1). The PCOPCs undergo end-capping reaction. Experimental procedures for end-capping reaction and conditions of DSC and WAXD analysis are all described in Supplementary Methods.

Especially, with the use of dichloromethane as an organic solvent, the complete conversion of epoxide was achieved in a prolonged time at room temperature, affording the polycarbonates with an enantioselectivity of $98 \%$ ee for $S, S$-configuration (Table 1 , entry 7 and Supplementary Fig. 2).
For comparison, the atactic $\mathrm{CO}_{2} / \mathrm{COPO}$ copolymer (PCOPC) was prepared using an irregular rac-2/PPNX (X=2,4-dinitrophenoxide) catalyst system (Table 1 , entry 8 and Supplementary Fig. 3). Although the accurate assignation of the microstructure of this polycarbonate proved to be very difficult, ${ }^{13} \mathrm{C}$ NMR study 
Table $2 \mid \mathrm{CO}_{2} / \mathrm{COPO} / \mathrm{CPO}$ terpolymerization mediated by $(\mathrm{S}, \mathrm{S}, \mathrm{S}, \mathrm{S})-1 / \mathrm{PPNX}$ catalyst system ${ }^{\star}$.

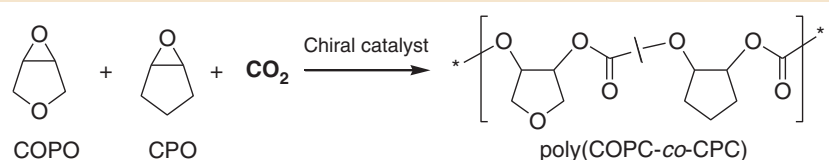

\begin{tabular}{|c|c|c|c|c|c|c|c|}
\hline Entry & Feed $^{\dagger}$ & Time (h) & TOF $^{\dagger}\left(h^{-1}\right)$ & COPC linkages ${ }^{\S}$ (mol\%) & $M_{\mathrm{n}} \|\left(\mathrm{kg} \mathrm{mol}^{-1}\right)$ & PDIII & $T_{g} / T_{m}$ \\
\hline 1 & COPO & 2 & 170 & 100 & $15.7^{\#}$ & $1.14^{\#}$ & $-/ 268$ \\
\hline 2 & $\mathrm{CPO}$ & 2 & 199 & 0 & 29.8 & 1.24 & $85 /-$ \\
\hline 3 & СОРО/СРО (1/9) & 3 & 87 & 30.6 & 15.6 & 1.16 & $89 /-$ \\
\hline 4 & СОРО/СРО $(3 / 7)$ & 3 & 96 & 69.0 & 16.0 & 1.20 & $109 / 208$ \\
\hline 5 & СОРО/СРО (1/1) & 3 & 108 & 84.2 & $16.9^{\#}$ & $1.14^{\#}$ & $122 / 245$ \\
\hline 6 & COPO/CPO $(7 / 3)$ & 2 & 146 & 92.3 & $16.4^{\#}$ & $1.16^{\#}$ & $124 / 261$ \\
\hline 7 & СОРО/СРО (9/1) & 2 & 161 & 98.0 & $17.3^{\#}$ & $1.20^{\#}$ & $-/ 265$ \\
\hline
\end{tabular}

${ }^{\star}$ The reaction was performed in neat epoxide $(30 \mathrm{mmol})$ in $20 \mathrm{ml}$ autoclave under $2.0 \mathrm{MPa} \mathrm{CO}$ pressure at $25^{\circ} \mathrm{C} .(\mathrm{S}, \mathrm{S}, \mathrm{S}, \mathrm{S})-\mathbf{1} / \mathrm{PPNX} / \mathrm{epoxide}=1 / 2 / 1,000(\mathrm{molar}$ ratio), $\mathrm{X}=2,4$-dinitrophenoxide. The selectivity for polycarbonates over cyclic carbonate and carbonate linkages of all the resultant polymers is $>99 \%$ based on ${ }^{1} \mathrm{H}$ NMR spectroscopy.

$\dagger$ Molar ratio.

$\ddagger$ Turnover frequency $(T O F)=$ mole of product (polycarbonates) $/ \mathrm{mol}$ of cat per hour.

$\S$ The COPC linkages contents in the terpolymer, determined by ${ }^{1} \mathrm{H}$ NMR spectroscopy.

Determined by gel permeation chromatography in DMF, calibrated with polystyrene.

- Determined by DSC analysis.

\#The polymer was heated to $280^{\circ} \mathrm{C}$ and determined by gel permeation chromatography in DMF.
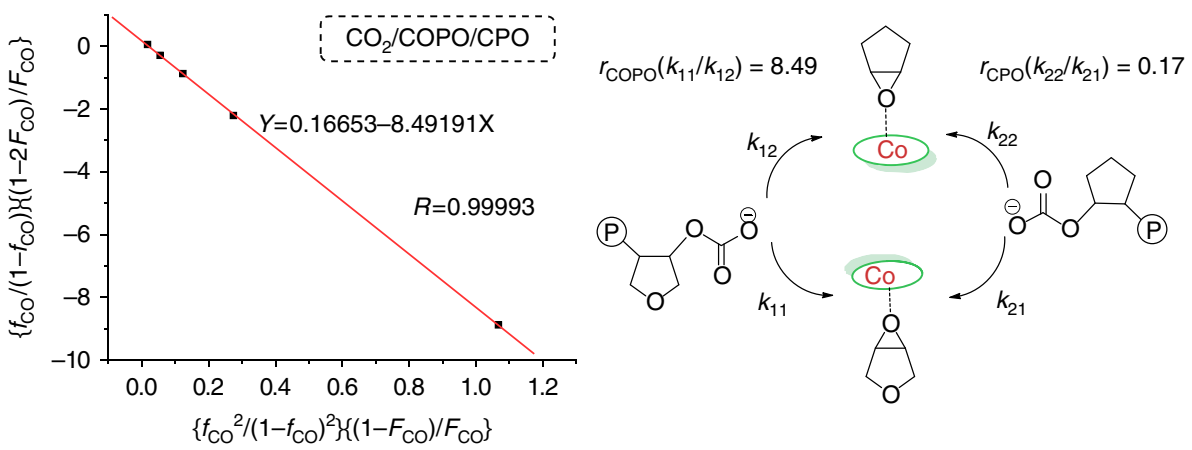

Figure 4 | Fineman-Ross plot and kinetic parameters for terpolymerization of $\mathrm{COPO} / \mathrm{CPO} / \mathrm{CO}_{2}$ by the dinuclear cobalt/PPNX catalyst system.

Experimental data are described in Supplementary Table 1.

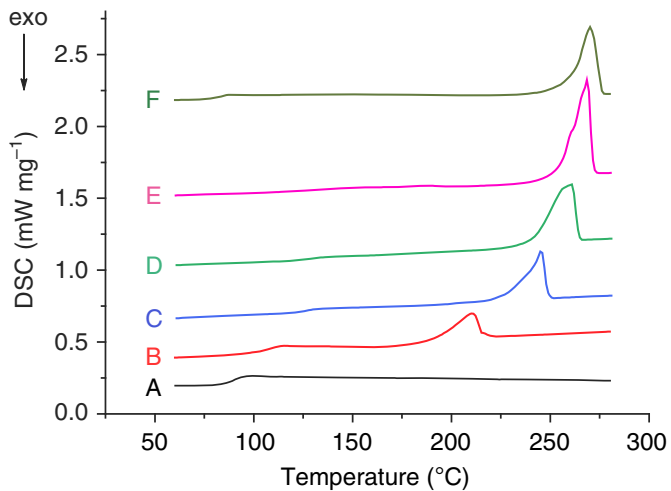

Figure 5 | DSC profiles of $\mathrm{CO}_{2} / \mathrm{COPO} / \mathrm{CPO}$ terpolymers. (A) With $30.6 \%$ COPC unit content (Table 2, entry 3), (B) with 69.0\% COPC unit content (entry 4), (C) with $84.2 \%$ COPC unit content (entry 5), (D) with $92.3 \%$ COPC unit content (entry 6), (E) with $98.0 \%$ COPC unit content (entry 7), (F) blend of (S)-PCPC (ee $>99 \%$, Table 2, entry 2)/(S)-PCOPC (ee $>99 \%$, Table 1, entry 3), 1/1 mass ratio.

could clearly reveal the significant difference in the methine region between the atactic and highly isotactic copolymers (Supplementary Fig. 4). Being different from the previous poly(cyclohexene carbonate)s and poly(cyclopentene carbonate)s (PCPC), the carbonyl group of the PCOPC showed negligible differences between the atactic and isotactic copolymers. The crystallization and melting behaviour of the polycarbonates were studied by means of differential scanning calorimetry (DSC) in a flowing nitrogen atmosphere. Only a single glass transition peak was observed at around $122^{\circ} \mathrm{C}$ for the atactic copolymers (Fig. 3, left plot, curve A). As the isotacticity of PCOPC has a critical influence on its crystallinity, it was found that the polycarbonates with moderate isotacticity $(\mathrm{ee}=85 \%)$ gave a weak $T_{\mathrm{g}}$ of $125^{\circ} \mathrm{C}$ and a melting endothermic peak at $265^{\circ} \mathrm{C}$ with the melting enthalpy $\left(\Delta H_{\mathrm{m}}\right)$ of $25.21 \mathrm{Jg}^{-1}$ (Fig. 3, left plot, curve C). Regarding the highly isotactic copolymer with $>99 \%$ ee, one should first notice that the $T_{\mathrm{g}}$ peak has disappeared completely, while a quite sharp and high crystallization endothermic peak is found at $271{ }^{\circ} \mathrm{C}$ with $\Delta H_{\mathrm{m}}=32.24 \mathrm{Jg}^{-1}$ (Fig. 3, left plot, curve $\mathrm{B})$, indicating a very high degree of crystallinity. Furthermore, the crystallization behaviour of highly isotactic polycarbonates was also confirmed by the wide-angle X-ray diffraction (WAXD) study. No diffraction was observed for the corresponding atactic copolymer, confirming its amorphous feature (Fig. 3, right plot, curve A). On the contrary, for highly isotactic ( $S$ )-copolymers, sharp diffraction peaks were observed at $2 \theta$ values of $18.1^{\circ}, 19.9^{\circ}$ and $23.2^{\circ}$, demonstrating that the isotactic copolymer was a typical semicrystalline polymer (Fig. 3, right plot, curve B). As expected, the thermo-gravimetric analysis revealed that the resulting polymer exhibited excellent thermal stability with a thermolysis temperature $>300^{\circ} \mathrm{C}$ (Supplementary Fig. 5 and Supplementary Methods). 
Synthesis of crystalline-gradient polycarbonates. Although the terpolymerization of $\mathrm{CO}_{2}$ with alicyclic or/and aliphatic epoxides was frequently reported using various organometallic catalysts $^{29-33}$, the synthesis of high stereoregular or crystallizable $\mathrm{CO}_{2}$-based terpolymers was never reported as a consequence of the lack of a highly enantioselective catalyst ${ }^{34}$. Since enantiopure dinuclear cobalt complex $\mathbf{1}$ is an excellent privileged catalyst for enantioselective copolymerization of $\mathrm{CO}_{2}$ with various mesoepoxides, it was applied to the terpolymerization of $\mathrm{CO}_{2}, \mathrm{COPO}$ and CPO. As expected, the binary $(S, S, S, S)-\mathbf{1} / \mathrm{PPNX}(\mathrm{X}=2,4$ dinitrophenoxide) catalyst system showed high activity for $\mathrm{CO}_{2} /$ $\mathrm{COPO} / \mathrm{CPO}$ terpolymerization at various epoxide ratios in the feedstock under $25^{\circ} \mathrm{C}$, selectively providing the terpolymers with different composition (Table 2). In the ${ }^{1} \mathrm{H}$ NMR spectrum of the resulting terpolymers in deuterated chloroform, the resonance of methine $\mathrm{CH}$ in the COPC unit is located at 5.30 p.p.m., whereas the $\mathrm{CH}$ in the cyclopentene carbonate $(\mathrm{CPC})$ unit is located at 5.02 p.p.m. (Supplementary Figs 8-10). Moreover, neither the polyether structure nor cyclic carbonate was detected during the terpolymerization. Notably, the enantioselectivity for COPC and CPC units in the terpolymers was the same as that found in the polycarbonates that resulted from the copolymerization of $\mathrm{COPO}$ or $\mathrm{CPO}$ alone with $\mathrm{CO}_{2}$. For example, the ee of cyclopentane-1,2diol and tetrahydrofuran-3,4-diol that resulted from the $\mathrm{CO}_{2} /$ COPO/CPO terpolymer was $99 \%$ and $95 \%$ for $(S, S)$ configuration, respectively, which is in accordance with the copolymerization described in Table 2, entries 1 and 2.

Surprisingly, $\mathrm{COPO}$ and $\mathrm{CPO}$ exhibited comparable reactivities in copolymerizing with $\mathrm{CO}_{2}$ catalysed by $(S, S, S, S)-\mathbf{1} / \mathrm{PPNX}$ ( $\mathrm{X}=2$,4-dinitrophenoxide) system, but a marked difference in reactivity was observed in the $\mathrm{CO}_{2} / \mathrm{COPO} / \mathrm{CPO}$ terpolymerization (Table 2). From the competition polymerization of $\mathrm{COPO}$ and $\mathrm{CPO}$ with $\mathrm{CO}_{2}$ using various epoxide feed ratios at room temperature, monomer reactivity ratios could be obtained $\left(r_{\mathrm{COPO}}=8.49\right.$ and $\left.r_{\mathrm{CPO}}=0.17\right)$ (Fig. 4 and Supplementary Table 1). These data indicated a much higher activity for the

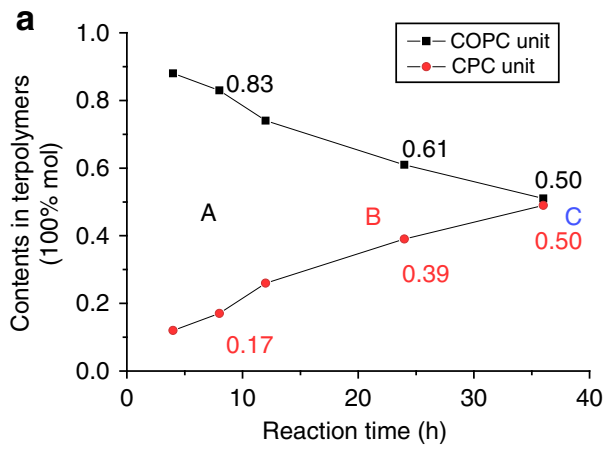

b
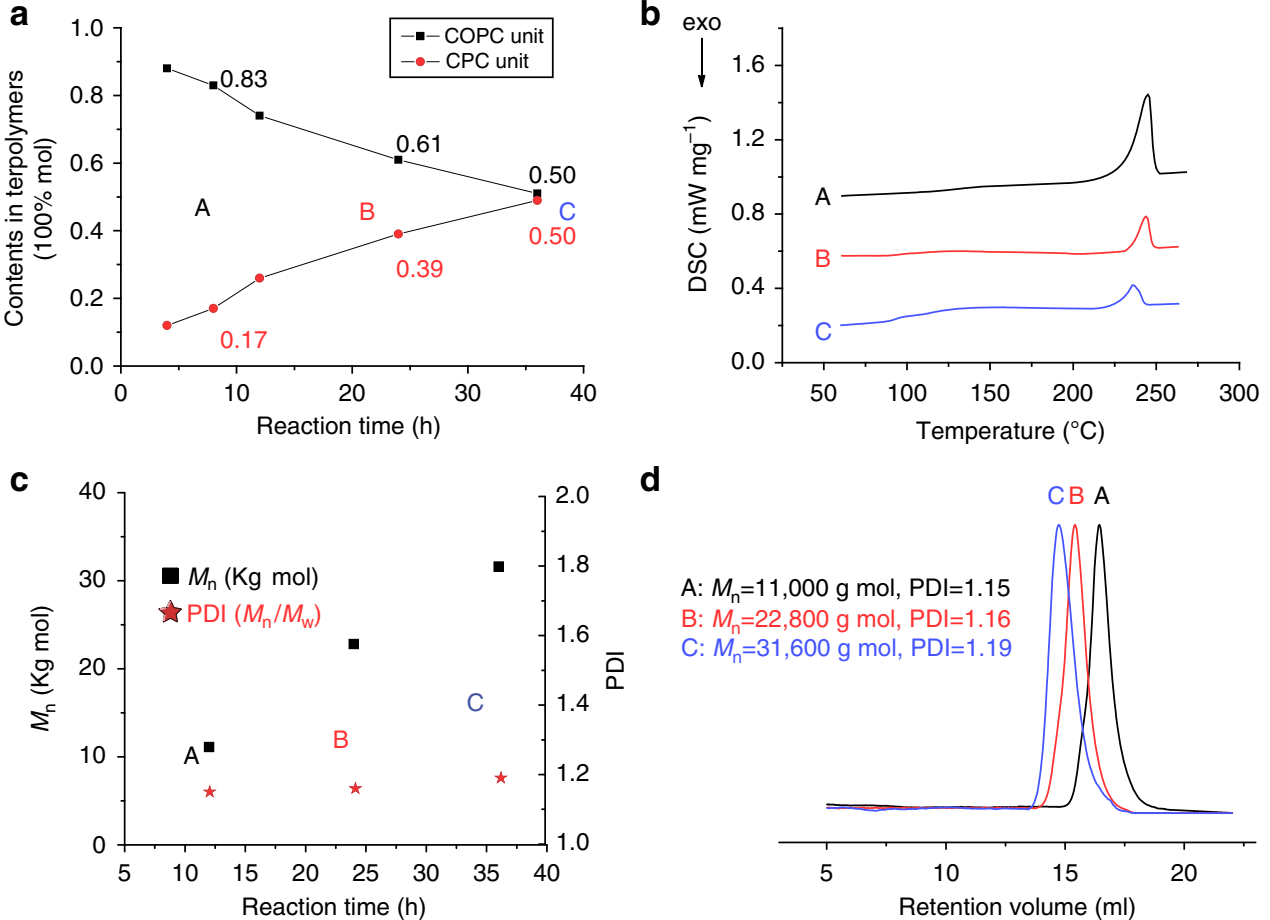

d

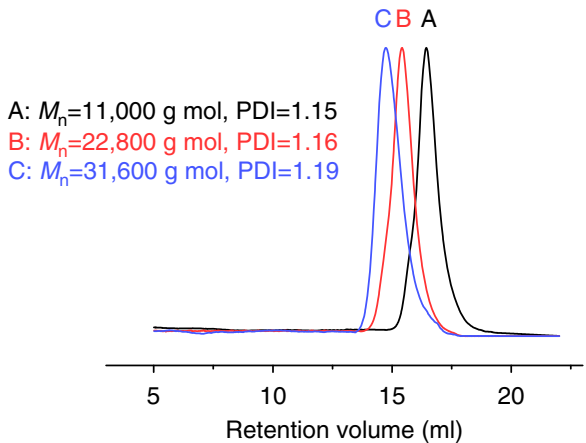

Figure 6 | Analysis of gradient polycarbonates. (a) Plot of the COPC and CPC carbonate unit contents in the resulting terpolymers versus the reaction time in the $\mathrm{COPO} / \mathrm{CPO} / \mathrm{CO}_{2}$ terpolymerization catalysed by $(\mathrm{S}, \mathrm{S}, \mathrm{S}, \mathrm{S})-\mathbf{1} / \mathrm{PPNX}$ system in dichloromethane (epoxide/dichloromethane $=1 / 2$ (molar ratio), 1/PPNX/COPO/CPO $=1 / 2 / 250 / 250$ (molar ratio), $X=2,4$-dinitrophenoxide) at $25^{\circ} \mathrm{C}$. (b) DSC profiles of gradient terpolymers at various time points: (A) $8 \mathrm{~h}$; (B) $24 \mathrm{~h}$; (C) $36 \mathrm{~h}$. (c) Plots of the terpolymer molecular weight and distribution versus the reaction time. (d) $\mathrm{GPC}$ traces of the $\mathrm{COPO} / \mathrm{CPO} / \mathrm{CO}_{2}$ terpolymers obtained at various time points: (A) $8 \mathrm{~h}$; (B) $24 \mathrm{~h}$; (C) $36 \mathrm{~h}$.
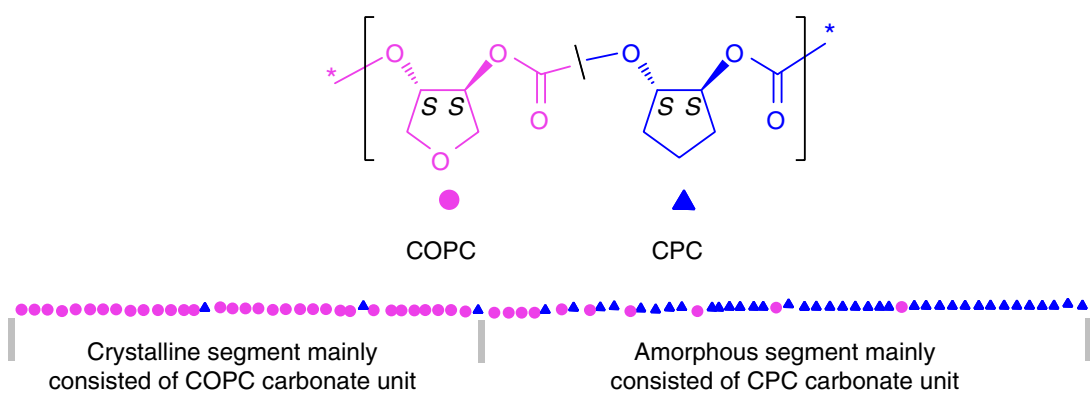

Figure 7 | Crystalline-gradient polycarbonates that resulted from $\mathbf{C P O} / \mathbf{C O P O} / \mathrm{CO}_{2}$ terpolymerization. Decrement of $\mathrm{COPC}$ carbonate unit and increment of CPC unit occur sequentially from one chain end to the other end. ${ }^{*}$ Repeat carbonate unit of polymers. 
synthesis of COPC-COPC linkages at the initial stage owing to the lower reactivity of $\mathrm{CPO}$ in the terpolymerization. The terpolymers with various COPC unit contents showed different melting behaviours, and the $T_{\mathrm{m}}$ was associated with the proportion of COPC unit content in the polymer (Fig. 5). When the COPC unit content was $98 \%$, the terpolymer showed a $T_{\mathrm{m}}$ of $265^{\circ} \mathrm{C}$ (Fig. 5, curve E). With decrease in the COPC unit content in the terpolymers, $T_{\mathrm{m}}$ was also decreased gradually and the appearance of a $T_{\mathrm{g}}$ was more and more obvious. When the COPC unit content was decreased to $30.6 \%$, the terpolymer became an amorphous material with a $T_{\mathrm{g}}$ of $89^{\circ} \mathrm{C}$ (Fig. 5, curve A), close to the $T_{\mathrm{g}}$ of the isotactic PCPC. It should be noted that a $T_{\mathrm{m}}$ of $270^{\circ} \mathrm{C}$ and a $T_{\mathrm{g}}$ of $84^{\circ} \mathrm{C}$ were detected in the blend of equivalent, isotactic (S)-PCPC and (S)-PCOPC (Fig. 5, curve F).

In order to determine the relationship between the COPC unit content in the terpolymers and the reaction time, ${ }^{1} \mathrm{H}$ NMR analysis was used to track the polymerization process by the intermittent sampling experiments. The terpolymerization was carried out with equimolar $\mathrm{COPO}$ and $\mathrm{CPO}$ in dichloromethane solution at $25^{\circ} \mathrm{C}$. COPO was predominantly copolymerized with $\mathrm{CO}_{2}$ at the beginning stage of the reaction because of its relative high reactivity, while CPO was incorporated into the terpolymer mainly at the high conversions (Fig. 6, plot-(a)). Since (S,S,S,S)-1/ PPNX-mediated $\mathrm{CO}_{2} /$ meso-epoxide copolymerization or terpolymerization exhibits a living polymerization character, a gradient distribution of COPC and CPC units in the terpolymers was formed. The decrement of COPC carbonate unit and the increment of CPC unit occur sequentially from one chain end to the other end, unlike traditional block or random copolymers (Fig. 7). As previously mentioned, highly isotactic PCOPCs are typical semicrystalline polymers, while both isotactic and atactic PCPCs are amorphous. As a result, the $\mathrm{COPO} / \mathrm{CPO} / \mathrm{CO}_{2}$ terpolymers with gradient distribution might show a unique crystalline-gradient nature. This means that the crystallinity varies continuously along the main chain, and the thermal properties of the terpolymers should depend on the COPC carbonate unit content. For example, when the reaction was performed for $8 \mathrm{~h}$, the terpolymers with the $83 \%$ COPC carbonate unit showed a $T_{\mathrm{m}}$ of $245^{\circ} \mathrm{C}$ (Fig. 6, plot-(b), curve A). With the increment of the reaction time, the $\Delta H_{\mathrm{m}}$ ascribed to PCOPC was reduced and the $T_{\mathrm{g}}$ ascribed to PCPC and/or incorporated with minor COPC units appeared. After $36 \mathrm{~h}$, the complete conversion of all epoxides was achieved, and the resultant terpolymers had a $T_{\mathrm{m}}$ of $241^{\circ} \mathrm{C}$ and a $T_{\mathrm{g}}$ of $106^{\circ} \mathrm{C}$ (Fig. 6, plot-(b), curve C). Especially, the isolated terpolymers that resulted from various time points all have narrow molecular weight distributions $(<1.2)$ and exhibit perfectly monomodal distribution. Although the $M_{\mathrm{n}}$ 's are lower than the expected values, a linear relationship between the conversion of epoxide and $M_{\mathrm{n}}$ of the resultant copolymers was found, which was consistent with the immortal polymerization characteristic (Fig. 6, plots-(c) and $(\mathrm{d}))^{35}$. However, it is worth noting here that the adventurous water or the addition of a protic agent such as methanol can cause chain transfer, thus resulting in the reduced molecular weight.

\section{Discussion}

In conclusion, we have demonstrated that the highly isotactic polycarbonate produced from the dinuclear cobalt complexmediated enantioselective copolymerization of $\mathrm{CO}_{2}$ with 3,4epoxytetrahydrofuran is a typical semicrystalline thermoplastic, and possesses a high $T_{\mathrm{m}}$ of $271{ }^{\circ} \mathrm{C}$ with $\Delta H_{\mathrm{m}}=32.24 \mathrm{Jg}^{-1}$. Also, the catalyst system was proved to be very effective in the enantioselective terpolymerization of $\mathrm{COPO}, \mathrm{CPO}$ and $\mathrm{CO}_{2}$, affording the terpolymers with gradient distribution of two kinds of carbonate units. The resultant terpolymers have unique crystalline-gradient nature, in which the crystallinity varies continuously along the main chain. Further study will focus on the terpolymerization of other meso-epoxides and develop more versatile $\mathrm{CO}_{2}$-based polycarbonates with morphology structure.

\section{Methods}

General. All manipulations involving air- and/or water-sensitive compounds were carried out in a glove box or with the standard Schlenk techniques under dry nitrogen. $\mathrm{CO}_{2}$ (99.995\%) was purchased from the Dalian Institute of Special Gases and used as received. Methylene chloride and DMSO were distilled from calcium hydride under nitrogen. CPO and COPO were purchased from Acros and distilled over calcium hydride.

Procedures for copolymerizing $\mathbf{C O}_{\mathbf{2}}$ with COPO. In a predried $20 \mathrm{ml}$ autoclave equipped with a magnetic stirrer, dinuclear cobalt catalyst $(0.030 \mathrm{mmol}$, 1 equiv) and PPNX ( $0.060 \mathrm{mmol}, 2$ equiv, $\mathrm{X}=2$,4-dinitrophenoxide) were dissolved in COPO (30 mmol, 1,000 equiv) in an argon atmosphere. $\mathrm{CO}_{2}$ was introduced into the autoclave for a designed pressure. The reaction mixture was stirred at a desired temperature for an appropriate time. After the allotted reaction time, $\mathrm{CO}_{2}$ was released, and the unreacted COPO was isolated under reduced pressure. A small amount of the resultant mixture was removed for ${ }^{1} \mathrm{H}$ NMR analysis to quantitatively give the selectivity of polycarbonate to cyclic carbonate, as well as carbonate linkages. The crude polymer was dissolved in $10 \mathrm{ml}$ DMSO and precipitated from methanol. This process was repeated 3-5 times to completely remove the catalyst, and white polymer was obtained by vacuum-drying.

Synthetic procedure of gradient terpolymer. In a predried $20 \mathrm{ml}$ autoclave equipped with a magnetic stirrer, dinuclear cobalt catalyst 1 ( $0.030 \mathrm{mmol}, 1$ equiv) and PPNX ( $0.060 \mathrm{mmol}, 2$ equiv, $\mathrm{X}=2,4$-dinitrophenoxide) were dissolved in COPO and CPO (1/1 molar ratio, $15 \mathrm{mmol}, 500$ equiv), and $\mathrm{CH}_{2} \mathrm{Cl}_{2}(2 \mathrm{ml})$ was added to the mixture under an argon atmosphere. $\mathrm{CO}_{2}$ was introduced into the autoclave for a designed pressure. The reaction mixture was stirred at a desired temperature for the appropriate time. Then $\mathrm{CO}_{2}$ was released, and a small amount of the resultant mixture was removed from the autoclave for ${ }^{1} \mathrm{H}$ NMR analysis to quantitatively give the selectivity of the polymer to cyclic carbonates, and carbonate linkages, as well as the composition of COPC and CPC units in the resultant terpolymers. The crude terpolymer was dissolved in $10 \mathrm{ml}$ DMSO and precipitated from methanol. This process was repeated 3-5 times to remove the catalyst, and white terpolymer was obtained by vacuum-drying. The resultant terpolymer was used for GPC and DSC analysis.

\section{References}

1. Aresta, M., Dibenedetto, A. \& Angelini, A. Catalysis for the valorization of exhaust carbon: from $\mathrm{CO}_{2}$ to chemicals, materials, and fuels. technological use of $\mathrm{CO}_{2}$. Chem. Rev. 114, 1709-1742 (2014)

2. Appel, A. M. et al. Frontiers, opportunities, and challenges in biochemical and chemical catalysis of $\mathrm{CO}_{2}$ fixation. Chem. Rev. 113, 6621-6658 (2013).

3. Omae, I. Recent developments in carbon dioxide utilization for the production of organic chemicals. Coord. Chem. Rev. 256, 1384-1405 (2012).

4. Sakakura, T., Choi, J. C. \& Yasuda, H. Transformation of carbon dioxide. Chem. Rev. 107, 2365-2387 (2007).

5. He, M., Sun, Y. \& Han, B. Green carbon science: scientific basis for integrating carbon resource processing, utilization, and recycling. Angew. Chem. Int. Ed. 52, 9620-9633 (2013).

6. Inoue, S., Koinuma, H. \& Tsuruta, T. Copolymerization of carbon dioxide and epoxide with organometallic compounds. Makromol. Chem. 130, 210-220 (1969).

7. Coates, G. W. \& Moore, D. R. Discrete metal-based catalysts for the copolymerization of $\mathrm{CO}_{2}$ and epoxides: discovery, reactivity, optimization, and mechanism. Angew. Chem. Int. Ed. 43, 6618-6639 (2004).

8. Darensbourg, D. J. Making plastics from carbon dioxide: salen metal complexes as catalysts for the production of polycarbonates from epoxides and $\mathrm{CO}_{2}$. Chem. Rev. 107, 2388-2410 (2007).

9. Kember, M. R., Buchard, A. \& Williams, C. K. Catalysts for $\mathrm{CO}_{2}$ /epoxide copolymerization. Chem. Commun. 47, 141-163 (2011).

10. Luinstra, G. A. Poly(propylene carbonate), old copolymers of propylene oxide and carbon dioxide with new interests: catalysis and material properties. Polym. Rev. 48, 192-219 (2008).

11. Klaus, S., Lehenmeier, M. W., Anderson, C. E. \& Rieger, B. Recent advances in $\mathrm{CO}_{2}$ /epoxide copolymerization-new strategies and cooperative mechanisms. Coord. Chem. Rev. 255, 1460-1479 (2011). 
12. Lu, X. B. \& Darensbourg, D. J. Cobalt catalysts for the coupling of $\mathrm{CO}_{2}$ and epoxides to provide polycarbonates and cyclic carbonates. Chem. Soc. Rev. 41, 1462-1484 (2012).

13. Qin, Y. \& Wang, X. Carbon dioxide-based copolymers: environmental benefits of PPC, an industrially viable catalyst. Biotech. J. 5, 1164-1180 (2010).

14. Wu, G. P. et al. Enhanced asymmetric induction for the copolymerization of $\mathrm{CO}_{2}$ and cyclohexene oxide with unsymmetric enantiopure salenCo(III) complexes: synthesis of crystalline $\mathrm{CO}_{2}$-based polycarbonate. J. Am. Chem. Soc. 134, 5682-5688 (2012).

15. Wu, G. P. et al. Crystalline $\mathrm{CO}_{2}$ copolymer from epichlorohydrin via $\mathrm{Co}(\mathrm{III})$-complex-mediated stereospecific polymerization. Macromolecules 46, 2128-2133 (2013).

16. Ren, W. M., Liang, M. W., Xu, Y. C. \& Lu, X. B. Trivalent cobalt complex mediated formation of stereoregular $\mathrm{CO}_{2}$ copolymers from phenyl glycidyl ether. Polym. Chem. 4, 4425-4433 (2013).

17. Liu, Y. et al. Stereospecific $\mathrm{CO}_{2}$ copolymers from 3,5-dioxaepoxides: crystallization and functionallization. Macromolecules 47, 1269-1276 (2014).

18. Coates, G. W. Precise control of polyolefin stereochemistry using single-site metal catalysts. Chem. Rev. 100, 1223-1252 (2000).

19. Miura, Y., Shibata, T., Satoh, K., Kamigaito, M. \& Okamoto, Y. Stereogradient polymers by ruthenium-catalyzed stereospecific living radical copolymerization of two monomers with different stereospecificities and reactivities. J. Am. Chem. Soc. 128, 16026-16027 (2006).

20. Ishitake, K., Satoh, K., Kamigaito, M. \& Okamoto, Y. Stereogradient polymers formed by controlled/living radical polymerization of bulky methacrylate monomers. Angew. Chem. Int. Ed. 48, 1991-1994 (2009).

21. Nakano, K., Kamada, T. \& Nozaki, K. Selective formation of polycarbonate over cyclic carbonate: copolymerization of epoxides with carbon dioxide catalyzed by a cobalt(III) complex with a piperidinium end-capping arm. Angew. Chem. Int. Ed. 45, 7274-7277 (2006).

22. Nakano, K., Hashimoto, S., Nakamura, M., Kamada, T. \& Nozaki, K. Stereocomplex of poly(propylene carbonate): synthesis of stereogradient poly(propylene carbonate) by regio- and enantioselective copolymerization of propylene oxide with carbon dioxide. Angew. Chem. Int. Ed. 50, 4868-4871 (2011).

23. Lee, B. Y. \& Cyriac, A. Making the gradient. Nat. Chem. 7, 505-507 (2011).

24. Darensbourg, D. J., Chung, W. C. \& Wilson, S. J. Catalytic coupling of cyclopentene oxide and $\mathrm{CO}_{2}$ utilizing bifunctional (salen) $\mathrm{Co}(\mathrm{III})$ and (salen) $\mathrm{Cr}$ (III) catalysts: comparative processes involving binary (salen) $\mathrm{Cr}$ (III) analogs. ACS Catal. 3, 3050-3057 (2013).

25. Liu, Y., Ren, W. M., Liu, J. \& Lu, X. B. Asymmetric copolymerization of $\mathrm{CO}_{2}$ with meso-epoxides mediated by dinuclear cobalt(III) complexes: unprecedented enantioselectivity and activity. Angew. Chem. Int. Ed. 52, 11594-11598 (2013)

26. Hirahata, W., Thomas, R. M., Lobkovsky, E. B. \& Coates, G. W. Enantioselective polymerization of epoxides: a highly active and selective catalyst for the preparation of stereoregular polyethers and enantiopure epoxides. J. Am. Chem. Soc. 130, 17658-17659 (2008).

27. Ahmed, S. M. et al. Enantioselective polymerization of epoxides using biaryllinked bimetallic cobalt catalysts: a mechanistic study. J. Am. Chem. Soc. 135, 18901-18911 (2013)

28. Ian Childers, M., Longo, J. M., Van Zee, N. J., LaPointe, A. M. \& Coates, G. W. Stereoselective epoxide polymerization and copolymerization. Chem. Rev. 114, 8129-8152 (2014).
29. Shi, L. et al. Asymmetric alternating copolymerization and terpolymerization of epoxides with carbon dioxide at mild conditions. Macromolecules 39, 5679-5685 (2006).

30. Seong, J. E., Na, S. J., Cyriac, A., Kim, B. W. \& Lee, B. Y. Terpolymerizations of $\mathrm{CO}_{2}$, propylene oxide, and various epoxides using a cobalt(III) complex of salen-type ligand tethered by four quaternary ammonium salts. Macromolecules 43, 903-908 (2010).

31. Ren, W. M. et al. Highly active, bifunctional Co(III)-salen catalyst for alternating copolymerization of $\mathrm{CO}_{2}$ with cyclohexene oxide and terpolymerization with aliphatic epoxides. Macromolecules 43, 1396-1402 (2010).

32. Wu, G. P., Xu, P. X., Zu, Y. P., Ren, W. M. \& Lu, X. B. Cobalt(III)-complexmediated terpolymerization of $\mathrm{CO}_{2}$, styrene oxide, and epoxides with an electron-donating group. J. Polym. Sci. Part A: Polym. Chem. 51, 874-879 (2013).

33. Darensbourg, D. J. et al. Highly selective and reactive (salan) $\mathrm{CrCl}$ catalyst for the copolymerization and block copolymerization of epoxides with carbon dioxide. Macromolecules 42, 6992-6998 (2009).

34. Lu, X. B., Ren, W. M. \& Wu, G. P. $\mathrm{CO}_{2}$ copolymers from epoxides: catalyst activity, product selectivity, and stereochemistry control. Acc. Chem. Res. 45, 1721-1735 (2012).

35. Aida, T. \& Inoue, S. Metalloporphyrins as initiators for living and immortal polymerizations. Acc. Chem. Res. 29, 39-48 (1996).

\section{Acknowledgements}

This work is supported by the National Natural Science Foundation of China (NSFC, Grant 21134002, 21104007), and Program for Changjiang Scholars and Innovative Research Team in University (IRT13008). X.-B.L. gratefully acknowledges the Chang Jiang Scholars Program (T2011056) from the Ministry of Education of the People's Republic of China

\section{Author contributions}

Y.L. synthesized the catalysts and performed catalytic experiments, measurements, the copolymer characterization and data analysis. W.-M.R. participated in the discussions and contributed important suggestions. K.-K.H. answered for the determination of enantiometric purity of the copolymer. X.-B.L. designed the research and conducted the experiments. X.-B.L. and Y.L. co-wrote the manuscript.

\section{Additional information}

Supplementary Information accompanies this paper at http://www.nature.com/ naturecommunications

Competing financial interests: The authors declare no competing financial interests.

Reprints and permission information is available online at http://npg.nature.com/ reprintsandpermissions/

How to cite this article: Liu, Y. et al. Crystalline-gradient polycarbonates prepared from enantioselective terpolymerization of meso-epoxides with $\mathrm{CO}_{2}$. Nat. Commun. 5:5687 doi: 10.1038/ncomms6687 (2014). 